\title{
Effect of steaming time on antioxidant properties of Napier grass herbal tea by green tea processing method
}

\author{
${ }^{1}$ Ng, K.S., ${ }^{1,2}$ Mohd Zin, Z., ${ }^{1}$ Mohd Maidin, N., ${ }^{3}$ Abdullah, M.A.A. and ${ }^{1 *}$ Zainol, M.K. \\ ${ }^{1}$ School of Food Science and Technology, Universiti Malaysia Terengganu, 21030, Kuala Nerus, \\ Terengganu, Malaysia. \\ ${ }^{2}$ Centre for Fundamental and Liberal Education, Universiti Malaysia Terengganu, 21030, Kuala Nerus, \\ Terengganu, Malaysia. \\ ${ }^{3}$ School of Fundamental Science, Universiti Malaysia Terengganu, Kuala Nerus, Terengganu, Malaysia
}

\section{Article history:}

Received: 21 July 2019

Received in revised form: 30 August 2019

Accepted: 1 September 2019

Available Online: 10

September 2019

\section{Keywords:}

Napier grass,

Antioxidant properties,

Herbal green tea,

Steaming

DOI:

https://doi.org/10.26656/fr.2017.4(1).263

\begin{abstract}
This study aimed to determine the effect of steaming time on antioxidant properties of Napier grass green tea. Napier grass was subjected to steaming for 1, 2, 3, 4, 6, 8 and 10 mins. Fresh and dried samples were extracted in water $\left(95^{\circ} \mathrm{C}, 30 \mathrm{mins}\right)$ and the extracts were then analysed by total phenolic content (TPC) assay, total flavonoid content (TFC) assay, diphenyl-picryl-hydrazyl (DPPH) assay, Ferric reducing antioxidant potential (FRAP) assay, ferric thiocyanate (FTC) method and thiobarbituric acid (TBA) method. Sample steamed for 8 mins showed the highest TPC (18.32 \pm 0.26$)$, TFC (152.71 \pm 5.74$)$ and 109.88 \pm 5.44 in FRAP assay. High antioxidant activity was found in sample steamed for 3 to $10 \mathrm{~min}(81.63 \pm 1.19$ to $83.50 \pm 1.10)$ in DPPH which were not significantly different with the fresh sample indicating steaming can retain the phytochemical compounds. Samples undergone 6 to 10 mins steaming time were found to have high lipid peroxidation in ferric thiocyanate $(75.02 \pm 2.96$ to $81.01 \pm 6.68)$ and thiobarbituric acid $(85.99 \pm 1.56$ to $86.21 \pm 1.44)$ assays. The results suggested that 8 mins of steaming time is suitable for Napier grass green tea as it exhibited the greatest antioxidant properties.
\end{abstract}

\section{Introduction}

Fruits, herbs, vegetables and various plants are natural sources of antioxidants (Balasundram et al., 2006; Andres-Lacueva et al., 2008; Brito et al., 2014). Numerous previous studies and reviews had reported the benefits of the intake of foods with high contents of natural antioxidants in disease prevention (Duthie and Bellizzi, 1999; Young and Woodside, 2001; Bennett et al., 2012; Hashemi et al., 2014; Sadowska-Bartosz and Bartosz, 2014; Zhang et al., 2015; Rani, 2017; Khan et al., 2018). The major compounds that contribute to the antioxidant activity in plants are phenolic compounds such as flavonoids and phenolic acids (Lin et al., 2016).

Various plants are considered as resources of traditional remedies, foods and beverages in Asia Pacific. Malaysia is one of the countries of the AsiaPacific region which is rich in plant species. Although many plant species have been used for food, industrial, cultural and medicinal purposes, there are still many underutilised plants (Arora, 2014). Napier grass (Pennisetum purpureum) is one of the underutilised plants. In Malaysia, it is commonly used as silage for animal feeds due to its high yield potential and drought tolerance (Lowe et al., 2003; Nyambati et al., 2011). Studies showed that high flavonoids content is found in Napier grass and it is a potential source of minerals, vitamins and dietary protein (Akah and Ani, 2014; Akah and Onweluzo, 2014; Ukpabi et al., 2015). Similarly, tea which is a common drink all over the world is also rich in various nutrients such as antioxidants, amino acids and vitamins (Hui et al., 2004; Mondal, 2007). Although there are studies reported on the high nutrient contents of Napier grass, the usage of Napier grass is restricted by limited knowledge regarding the processing technique in food production. Therefore, it is interesting to explore the potential of Napier grass in the production of herbal tea by tea processing method.

In tea processing, steaming helps to retain the antioxidant components, appearance and texture of the products. It is also one of the important steps in tea making process because over steaming can damage the leaves while insufficient steaming can initiate the onset of the fermentation (Singh et al., 2014). When tea fermentation occurs, organoleptic and antioxidant properties of the tea could be affected (Rodrigues et al., 
2016). Steaming times in green tea making process are varied in different manufacturer. The time is in the range of $35 \mathrm{~s}$ to up to 2 mins depends on the manufacturer (Turkmen et al., 2009; Carloni et al., 2013; Singh et al., 2014). Beside tea leaves, the optimal steaming time for various plant materials is different depends on the species of the leaves (Saikia and Mahanta, 2013). There are many studies of the effect of steaming on antioxidant properties of different plant materials such as litchi pericarp (Kessy et al., 2016), red pepper (Hwang et al., 2012) and eggplant (Chumyam et al., 2013). These previous studies show that steaming has different influences on phytochemical in various plant materials. However, the lack of information is available in the literature about the effect of steaming time on Napier grass. Therefore, the study on the impact of steaming on the bioactive compounds is important in the development of Napier grass tea. This study is aimed to determine the effect of steaming time on antioxidant properties of Napier grass tea.

\section{Materials and methods}

Fresh Napier grass was obtained from Kuala Berang, Terengganu. The leaves were cleaned with tap water to clean the soil and dust. After that, cleaned leaves were blotted with tissue papers to absorb water and allowed to dry for 10 mins at $25 \pm 1^{\circ} \mathrm{C}$.

\subsection{Preparation of Napier grass tea by green tea processing method with different steaming time}

A total of $50 \mathrm{~g}$ of the cut Napier grass $(0.5 \mathrm{~cm})$ was steamed for different time (1, 2, 3, 4, 6, 8 and 10 mins) using a steamer pot with $30 \mathrm{~cm}$ diameter. The sample was then placed into a $22.9 \mathrm{~cm} \times 16.4 \mathrm{~cm}$ zip-lock plastic bag with $0.08 \mathrm{~mm}$ thickness and soaked in icy cold water for $30 \mathrm{~s}$ to stop the cooking process. Then, the sample was dried at $50^{\circ} \mathrm{C}$ for $7 \mathrm{~h}(<6 \%$ moisture content $)$. Dried Napier grass was ground and sieved through a $1 \mathrm{~mm}$ metal sieve (Carloni et al., 2013; Lusia Barek et al., 2015 with modifications).

\subsection{Preparation of Napier grass green tea infusion (hot water extraction)}

Dried Napier grass was ground using a waring blender (Waring Commercial, Torrington. CT, U.S.A) with a particle size less than $1 \mathrm{~mm}$ metal sieve. Two grams of powdered Napier grass was infused in $200 \mathrm{~mL}$ distilled water $\left(95^{\circ} \mathrm{C}\right)$ and stirred for 2 mins using a magnetic stirrer. On the other hand, infusion of fresh Napier grass was used as a control in all experiments. A total of $5 \mathrm{~g}$ of fresh Napier grass was ground using a waring blender (Waring Commercial, Torrington. CT, U.S.A). The ground fresh Napier grass was then infused in $200 \mathrm{~mL}$ of distilled water $\left(95^{\circ} \mathrm{C}\right)$ and continuously stirred for 2 mins using a magnetic stirrer.

All the infusions were left to cool for $30 \mathrm{~min}$ of infusion time before filtered through a Whatman No.1 filter paper. After cooling down to room temperature, tea infusions were stored at $-20^{\circ} \mathrm{C}$ until analysis.

\subsection{Antioxidant properties assays}

\subsubsection{Determination of total phenolic content (TPC)}

Folin Ciocalteu's method was used to measure the TPC. Aliquots of sample $(1 \mathrm{~mL})$ and gallic acid with different concentrations $(10,20,40,60,80,100 \mu \mathrm{g} / \mathrm{mL})$ were transferred into the test tubes. Then, $5 \mathrm{~mL}$ of distilled water and $0.5 \mathrm{~mL}$ of Folin Ciocalteu's reagent were added into each test tube and shaken. After 5 mins, $1.5 \mathrm{~mL}$ of $20 \%(\mathrm{~m} / \mathrm{v})$ sodium carbonate was added and the volume was made up to $10 \mathrm{~mL}$ with distilled water. The samples were incubated for $2 \mathrm{hrs}$ at room temperature. After incubation, absorbance was measured at $750 \mathrm{~nm}$ using UV-visible spectrophotometer (SHIMADZU, Kyoto, Japan). The data for TPC of tea infusion was expressed as $\mathrm{mg}$ of gallic acid equivalent weight (GAE)/200 mL infusion (Kamtekar et al., 2014).

\subsubsection{Determination of total flavonoid content (TFC)}

Aluminium chloride colorimetric assay was used to measure the TFC. A total of $1 \mathrm{mg}$ of aliquots and $1 \mathrm{~mL}$ quercetin with different concentrations $(100,200,400$, $600,800,1000 \mu \mathrm{g} / \mathrm{mL}$ ) were added into test tubes. Then, $4 \mathrm{~mL}$ of distilled water and $0.3 \mathrm{~mL}$ of $5 \%(\mathrm{~m} / \mathrm{v})$ sodium nitrite solution were added into each test tubes. After 5 mins, $0.3 \mathrm{~mL}$ of $10 \%(\mathrm{~m} / \mathrm{v})$ aluminium chloride was added. At $6^{\text {th }}$ min, $2 \mathrm{~mL}$ of $1 \mathrm{M}$ sodium hydroxide was added. Finally, volume was made up to $10 \mathrm{~mL}$ with distilled water. The absorbance was measured at $510 \mathrm{~nm}$ using UV-visible spectrophotometer (SHIMADZU, Kyoto, Japan). The data of TFC of tea infusion was expressed as $\mathrm{mg}$ of quercetin equivalents (QE)/200 mL infusion (Kamtekar et al., 2014).

2.3.3 Free radical scavenging ability of $D P P H$ radical (1,1-diphenyl-2-picryl hydrazyl)

DPPH test was performed using the method of Barku, Opoku-Boahen, Owusu-Ansah and Mensah (2013) with some modifications. An aliquot of $2 \mathrm{~mL}$ of $0.004 \%(\mathrm{~m} / \mathrm{v}) \mathrm{DPPH}$ solution in methanol and $1 \mathrm{~mL}$ of plant extract were incubated at $25^{\circ} \mathrm{C}$ for 45 mins. The absorbance of the test mixture was read at $517 \mathrm{~nm}$ using a UV-visible spectrophotometer (SHIMADZU, Kyoto, Japan) against a DPPH control containing only $1 \mathrm{~mL}$ of distilled water in place of the extract. Percent inhibition was calculated using the following expression:

$$
\% \text { Inhibition }=\left(\mathrm{A}_{0}-\mathrm{A}_{\mathrm{t}} / \mathrm{A}_{0}\right) \times 100
$$


Where $A_{0}$ and $A_{t}$ is the absorption of the blank sample and the absorption of tested extract solution, respectively.

\subsubsection{Ferric reducing antioxidant potential (FRAP) assay}

The FRAP reagent was prepared by $300 \mathrm{mM}$ sodium acetate buffer (pH 3.6), $20 \mathrm{mM}$ iron chloride and $10 \mathrm{mM}$ 2,4,6-tripyridyl-s-triazine dissolved in $40 \mathrm{mM}$ hydrochloric acid at a ratio of 10:1:1 (v:v:v). After mixing, the reagent was allowed to incubate at $37^{\circ} \mathrm{C}$ for 5 mins before use. The initial reading of the reagent was measured at $593 \mathrm{~nm}$ using a UV-visible spectrophotometer (SHIMADZU, Kyoto, Japan). An aliquot of $0.1 \mathrm{~mL}$ of tea infusion was then added to 2.9 $\mathrm{ml}$ of FRAP reagent and kept in the dark for 30 mins. Trolox solution was used to create the calibration curves. Results were expressed as $\mu \mathrm{mol}$ Trolox equivalents (TE)/200 mL infusion (Benzie and Strain, 1996; Heong et al., 2011).

\subsubsection{Ferric thiocyanate (FTC) assay}

The inhibitory effect of the plant against oxidation by peroxides was evaluated by the modified method of Udaya Prakash et al. (2014). A total of $2 \mathrm{~mL}$ of $2.51 \%$ $(\mathrm{v} / \mathrm{v})$ linoleic acid in ethanol, $120 \mu \mathrm{L}$ of $98 \%$ ethanol and $9 \mathrm{~mL}$ of $40 \mathrm{mM}$ phosphate buffer ( $\mathrm{pH} \mathrm{7)}$ were added to $100 \mu \mathrm{L}$ of the plant extract. The mixture was incubated in dark, at $40^{\circ} \mathrm{C}$. To $100 \mu \mathrm{L}$ of the mixture, $9.7 \mathrm{~mL}$ of $75 \%(\mathrm{v} / \mathrm{v})$ ethanol, $100 \mu \mathrm{L}$ of $30 \%(\mathrm{~m} / \mathrm{v})$ ammonium thiocyanate and $100 \mu \mathrm{L}$ of $20 \mathrm{mM} \mathrm{FeCl} 3$ in $3.5 \%(\mathrm{v} / \mathrm{v})$ $\mathrm{HCl}$ were added. The absorbance of the solution was measured at $500 \mathrm{~nm}$, after 3 mins. Butylated hydroxytoluene (BHT) (200 ppm) and $\alpha$-tocopherol (200 $\mathrm{ppm})$ were used as standards. The percentage of inhibition was calculated using the following equation:

$$
\% \text { Inhibition }=\left(\mathrm{A}_{0}-\mathrm{A}_{\mathrm{t}} / \mathrm{A}_{0}\right) \times 100
$$

Where $A_{0}$ and $A_{t}$ is the absorption of the blank sample and the absorption of tested extract solution, respectively.

\subsubsection{Thiobarbituric acid (TBA) assay}

Thiobarbituric acid assay was evaluated following the modified method of Udaya Prakash et al. (2014). A total of $2 \mathrm{~mL}$ each of $20 \%(\mathrm{~m} / \mathrm{v})$ trichloroacetic acid (TCA) and $0.67 \%(\mathrm{~m} / \mathrm{v})$ thiobarbituric acid (TBA) were mixed with $1 \mathrm{~mL}$ sample. The solution was heated in boiling water bath for 10 mins. After cooling, the solution was centrifuged at $3000 \mathrm{rpm}$. The absorbance of the supernatant was measured at $532 \mathrm{~nm}$. Butylated hydroxytoluene (BHT) (200 ppm) and a-tocopherol (200 ppm) were used as standards. The percentage of inhibition was calculated using the following equation:

$\%$ Inhibition $=\left(\mathrm{A}_{0}-\mathrm{A}_{\mathrm{t}} / \mathrm{A}_{0}\right) \times 100$

Where $A_{0}$ and $A_{t}$ is the absorption of the blank sample and the absorption of tested extract solution, respectively.

\subsection{Statistical analysis}

Data were expressed as means \pm standard deviation (SD) of triplicates. All data were submitted to one-way analysis of variance (ANOVA) using SPSS (version 20) software. The values were considered to be significantly different when $\mathrm{P}<0.05$. The correlations among antioxidant assays were calculated using the Pearson's correlation coefficient.

\section{Results and discussion}

\subsection{Determination of total phenolic content (TPC)}

These findings (Figure 1) showed that the TPC of Napier grass was significantly affected by the steaming time. TPC of Napier grass without steaming $(0 \mathrm{~min})$ was $15.37 \pm 0.11$. The TPC of Napier grass was significantly decreased to $14.24 \pm 0.21$ at 1 min of steaming time. This might be caused by insufficient steaming of Napier grass that might elevate the degradation of the bioactive compounds (Kessy et al., 2016).

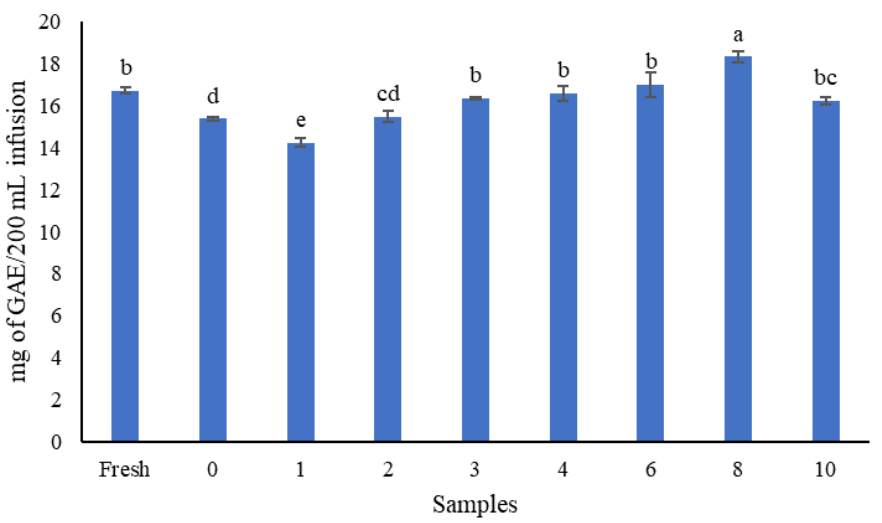

Figure 1. TPC of infusions of Napier grass undergone different steaming time. Different alphabets on each histogram indicates significant difference at $\mathrm{p}>0.05$.

TPC of Napier grass steamed for 3, 4, 6 and 10 mins were not significantly different with that of fresh Napier grass (16.71 \pm 0.15$)$. Moreover, the highest TPC was obtained at 8 mins $(18.32 \pm 0.26)$ indicates that steaming can retain and increase TPC in Napier grass. Numerous previous studies reported that steaming can improve antioxidant properties of plant materials. A study by Chumyam et al. (2013) reported that eggplant steamed for 5 to 15 mins was found to have significantly higher TPC than those of raw material. This result was also in accordance with the study by Kessy et al. (2016) which 
revealed that litchi pericarp that undergone 3 mins steaming and drying at $60^{\circ} \mathrm{C}$ showed a higher TPC compared to raw sample. A study of phytochemicals in green leafy Thai vegetables by Nartnampong et al. (2016) also found that asiatic pennywort, garden parsley, peninsular, swamp morning glory and sweet basil showed higher TPC after steaming for 5 mins. Other plant samples such as banana blossom, cauliflower floret, beetroot, teasle gourd, cabbage and tomato also showed an increased TPC on steaming (Saikia and Mahanta, 2013).

Increased in TPC in sample undergone $8 \mathrm{~min}$ steaming time might be caused by the breakdown of cellular constituents which release bound phenolic compounds from the ester bonds due to thermal process (Dewanto et al., 2002; Adefegha and Oboh, 2011; Hwang et al., 2012; Saikia and Mahanta, 2013; Kessy et al., 2016; Geetha et al., 2018). The improved release of phenolic compounds might also be caused by the inactivation of oxidative enzymes (Saikia and Mahanta, 2013; Yuniartini et al., 2015; Kessy et al., 2016). In addition, heat treatment causes the degradation of tannins into simple phenolic compounds, whereas steaming treatment leads to the hydrolysis of tannic acid into galloyl like gallotanin, which in turn, increase the TPC (Yuniartini et al., 2015).

In contrast, a study by Hwang et al. (2012) carried out for red pepper demonstrated that steaming for 5 to 15 mins leads to significant loss of TPC in red pepper compared to raw sample. Kalkan and Yucecan (2013) reported that steaming causes loss of TPC in squash, eggplant and potato. Similarly, TPC of green pea, black eye pea, bottle gourd and radish was decreased after steaming for 5 to 6 mins (Saikia and Mahanta, 2013).

TPC in Napier grass was slightly decreased at 10 min steaming time which was $16.23 \pm 0.17$ compared to the sample steamed for 8 mins which were $18.32 \pm 0.26$. Factors that cause loss of TPC include processing time and food size (Hwang et al., 2012). Therefore, $10 \mathrm{mins}$ of steaming might start to cause loss of phenolic compound due to thermal degradation of bioactive compounds. A study by Bamidele et al. (2017) reported that further blanching time which more than 5 mins could cause significant reduction in TPC of green leafy vegetables.

\subsection{Determination of total flavonoid content (TFC)}

Figure 2 shows that TFC of Napier grass undergone steaming process was significantly increased with increasing steaming time until 8 mins $(152.71 \pm 5.74)$ compared to the fresh Napier grass and was reduced slightly but not significantly at $10 \mathrm{~min}(130.93 \pm 11.02)$ compared to the sample steamed for 8 mins. Similar to the result of TPC, it showed that steaming can retain and improve TFC of Napier grass. It also indicated a possible release of certain flavonoids during the steaming of the samples (Kessy et al., 2016). These findings are in accordance with the study by Kessy et al. (2016) which reported that steaming could improve TFC of litchi pericarp. Enhancement of TFC was also reported in green leafy vegetables such as cabbage (Saikia and Mahanta, 2013), Cleome gynandra leaves (Moyo et al., 2016), waterleaf, green amaranth, Chaya and wild basil (Adefegha and Oboh, 2011) after steaming.



Figure 2. TFC of infusions of Napier grass undergone different steaming time. Different alphabets on each histogram indicates significant difference at $\mathrm{p}>0.05$.

TFC of dried Napier grass without steaming (97.82 \pm 13.00$)$ was higher than that of fresh $(81.38 \pm 3.85)$ and steamed samples have undergone steaming for 1 to 3 mins $(80.93 \pm 12.22$ to $88.93 \pm 2.31)$. TFC of Napier grass might be affected by the preparation process. The dried Napier grass without steaming was dried within the shortest time possible after washing and cutting whereas the steamed samples have undergone 1,2 and 3 mins steaming showed no significant difference with that of fresh Napier grass indicating 1 to 3 mins steaming was insufficient to inhibit the enzymatic degradation. The short period of steaming might also elevate the degradation of the bioactive compounds because short steaming time could provoke enzymatic reaction (Kessy et al., 2016).

The highest TFC was found in Napier grass steamed for 8 mins $(152.71 \pm 5.75)$. There was an agreement between the result of TPC and TFC which found that sample undergone 8 mins of steaming exhibited the highest TPC. Furthermore, this result coincided with the previous study where correlations were established between TPC and TFC (Adefegha and Oboh, 2011).

Numerous previous studies reported that steaming affects the flavonoid content of various plant materials. Based on these previous reports, steaming had positive and negative effects on TFC of plants (Dewanto et al., 
2002; Saikia and Mahanta, 2013; Kessy et al. 2016). Saikia and Mahanta (2013) revealed that TFC in beetroot, cabbage, radish, tomato, kharua brinjal, knolknol and carrot were enhanced after steaming. Improvement in TFC possibly because the bound phenolic compounds were released from plant cell constituent that had been thermally damaged during heating (Dewanto et al., 2002; Kessy et al. 2016). In contrast, the negative effects of steaming on TFC was found in banana blossom, cauliflower, green pea, teasle gourd, black eye pea, bottle gourd and roselle leaves (Saikia and Mahanta, 2013).

The presence of phenolic and flavonoids compounds in Napier grass has shown its nutritional value and also its antioxidant role in protecting organism from free radicals that cause ageing and chronic diseases such as cancers, diabetes and cardiovascular diseases (Gramza et al., 2005; Irina and Mohamed, 2012; Kalkan and Yücecan, 2013; Gunathilake and Ranaweera, 2016; Nobosse et al., 2017). Therefore, based on the result of TPC and TFC of this study, consumption of Napier grass tea could be beneficial to body health.

\subsection{Free radical scavenging ability of DPPH radical (1,1 -diphenyl-2-picryl hydrazyl)}

Figure 3 shows that DPPH scavenging activity of Napier grass was significantly changed after steaming. Dried Napier grass without steaming $(0 \mathrm{~min})$ showed the highest DPPH scavenging activity $(90.02 \pm 1.11)$ followed by samples have undergone steaming for 6 mins $(86.14 \pm 0.35)$ and $8 \mathrm{~min}(86.32 \pm 0.09)$. There is no significant difference between raw sample and samples steamed for 3 to $10 \mathrm{~min}(81.63 \pm 1.19$ to $83.50 \pm 1.10)$ indicating that steaming can retain the phytochemical compounds. These phytochemical compounds act as radical scavengers which play an important role in preventing the chain initiation step of reactive species such as free radicals (Adefegha and Oboh, 2011).



Figure 3. Percentage of inhibition of DPPH free radical scavenging activity of infusions of Napier grass undergone different steaming time. Different alphabets on each histogram indicates significant difference at $\mathrm{p}>0.05$.
Adefegha and Oboh (2011) revealed that DPPH scavenging ability of green leafy vegetables (waterleaf, Senecio biafrae, green amaranth, wild basil, sweet potato leaf, fluted pumpkin and Chaya leaves) was significantly increased after steaming for 10 mins.

In contrast, a study by Preti et al. (2017) carried out for green bean varieties demonstrated that steaming green beans for 15 min lead to loss of DPPH free radical scavenging ability due to thermal degradation. Hwang et al. (2012) also reported that DPPH scavenging activity of red pepper was reduced by $23.5-30.3 \%$ after steaming. From the previous study, we can see that steaming could have different effects on the antioxidant activity of different plant materials. Besides cooking time, other factors that affect antioxidant activity of food include method of cooking, temperature and portion size (Hwang et al., 2012).

Although DPPH is a common method used to determine the free radical scavenging ability, it has a limitation of colour interference and sample solubility (Adefegha and Oboh, 2011). Moreover, the complex nature of phytochemicals in plants causes difficulty in evaluating their total antioxidant properties (Gunathilake and Ranaweera, 2016). Therefore, more than one methods such as FRAP, FTC and TBA assays were employed in order to study the antioxidant properties of Napier grass.

\subsection{Ferric reducing antioxidant potential (FRAP) assay}

FRAP assay was done to study the reducing ability of antioxidants against oxidative effects of reactive oxygen species (Sarla et al., 2011). The findings (Figure 4) showed that antioxidant activity of Napier grass was significantly increased to $91.71 \pm 4.14$ at 4 mins of steaming time indicating that Napier grass showed increased ferric reducing antioxidant potential upon steaming. Similarly, TFC of Napier grass was also

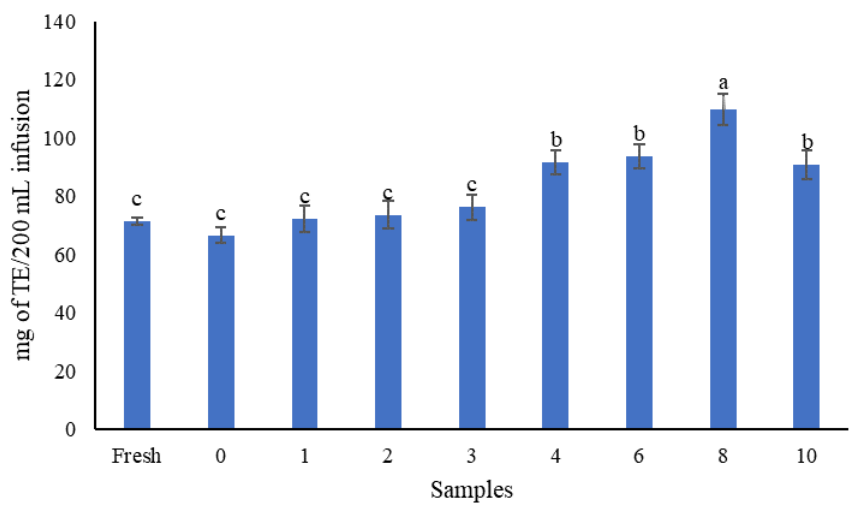

Figure 4. Ferric reducing antioxidant potential of infusions of Napier grass undergone different steaming time. Different alphabets on each histogram indicates significant difference at $\mathrm{p}>0.05$. 
increased significantly at 4 mins of steaming compared to the fresh Napier grass.

No significant change was observed between the fresh sample $(71.31 \pm 1.30)$ and samples undergone 0 to 3 min of steaming (66.62 \pm 2.77 to $76.26 \pm 4.39)$. However, the antioxidant activity of samples underdone steaming (1 to 3 mins) was slightly higher than that of dried sample without steaming $(66.62 \pm 2.77)$. This can be explained by the fact that oxidative enzymatic reaction that occurs in the leaves during drying process is terminated by the steaming treatment thereby reducing further oxidative damage during drying (Nobosse et al., 2017).

The highest antioxidant activity was $109.88 \pm 5.44$ which found in the sample undergone 8 mins steaming. This result is in accordance with that of TPC and TFC indicating that phenolic compounds and flavonoids contribute to the antioxidant activity of Napier grass. Studies show that phenolic compounds in plants act as antioxidants by scavenging free radicals, chelating metals and inhibiting the activity of oxidases (Wiczkowski and Piskula, 2004; Nartnampong et al., 2016).

\subsection{Ferric thiocyanate (FTC) assay}

FTC assay was done to determine the lipid peroxidation inhibition of Napier grass infusion. The results (Figure 5) show that sample steamed for $10 \mathrm{mins}$ $(81.01 \pm 6.68)$ showed the highest percentage of inhibition among the Napier grass samples. This result was different from that of FRAP where 8 mins of steaming was the optimum steaming time for Napier grass. These findings showed that longer steaming time improves antioxidant activity of Napier grass. This might be caused by the termination of enzymatic reaction and the release of certain phenolic compounds from the damaged plant cell constituents during steaming (Dewanto et al.,

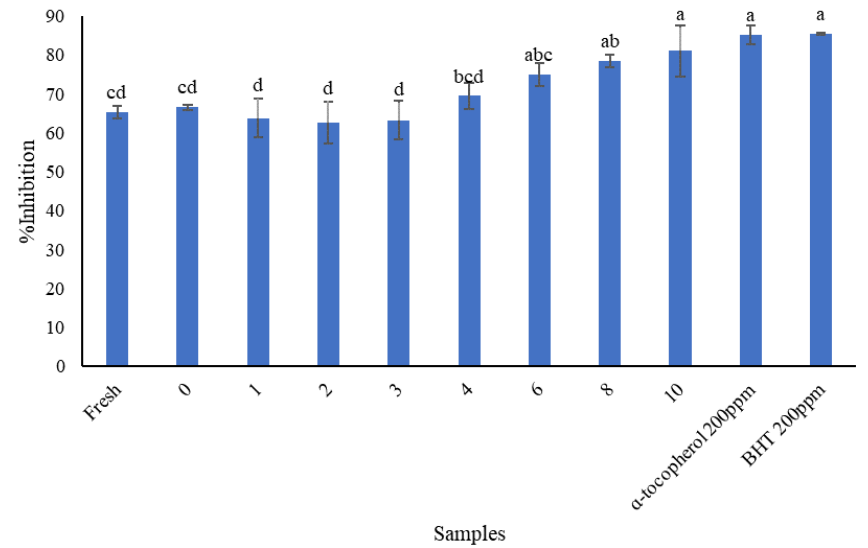

Figure 5. Lipid peroxidation inhibition of infusions of Napier grass undergone different steaming time by FTC assay. Different alphabets on each histogram indicates significant difference at $\mathrm{p}>0.05$.
2002; Adefegha and Oboh, 2011; Hwang et al., 2012; Kessy et al., 2016; Geetha et al., 2018). Phenolic compounds and flavonoids contribute greatly to the antioxidant activity and play role in the prevention of lipids peroxidation (Nobosse et al., 2017).

In FTC assay, lipophilic antioxidants which are $\alpha$ tocopherol $(85.17 \pm 2.52)$ and BHT $(85.52 \pm 0.30)$ showed stronger antioxidant activity in emulsions as they concentrate at the lipid/air surface (Kulišić et al., 2006). However, there is no significant difference between the lipid peroxidation inhibition of samples steamed for 6 to 10 mins $(75.02 \pm 2.96$ to $81.01 \pm 6.68)$ and the lipophilic antioxidants used in this assay. This can be explained by the characteristics of plant flavonoids as they can be classified into lipophilic and hydrophilic ones depending on their solubility pattern (Wiczkowski and Piskula, 2004; Saikia and Mahanta, 2013).

\subsection{Thiobarbituric acid (TBA) assay}

Figure 6 shows the lipid peroxidation inhibition of samples against the secondary stage of lipid peroxidation. Similar to the result of FTC, all the Napier grass samples have lower inhibitory effects than that of positive controls ( $\alpha$-tocopherol and BHT). However, the findings of samples steamed for 6 to $10 \mathrm{mins}$ $(85.99 \pm 1.56$ to $86.21 \pm 1.44)$ have no significant difference with that of positive controls. This showed that the addition of Napier grass infusion to the linoleic acid emulsion was able to reduce lipid peroxidation.

Samples steamed for 1 to 4 mins $(72.58 \pm 2.94$ to $74.63 \pm 0.77)$ showed significant low lipid peroxidation inhibition. However, these samples had no significant difference with that of fresh sample $(78.98 \pm 10.14)$ and the sample without steaming $(78.16 \pm 0.96)$ indicating 1 to 4 mins of steaming time did not affect the antioxidant activity of Napier grass.

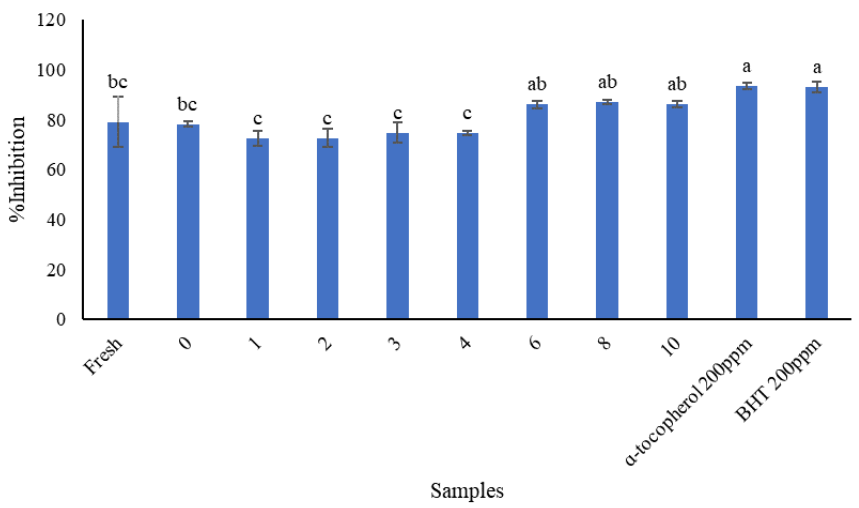

Figure 6. Lipid peroxidation inhibition of infusions of Napier grass undergone different steaming time by TBA assay. Different alphabets on each histogram indicates significant difference at $\mathrm{p}>0.05$.

(C) 2019 The Authors. Published by Rynnye Lyan Resources 
Flavonoid aglycones are characterised by hydrophobic properties (Wiczkowski and Piskula, 2004). Most of the flavonoids occur naturally in the glycosidic form except for catechins (flavan-3-ols) which appear as aglycones (Wiczkowski and Piskula, 2004; Thilakarathna and Rupasinghe, 2013). The presence of glycoside in flavonoid molecule increases the hydrophilicity of flavonoids (Wiczkowski and Piskula, 2004). The antioxidant properties of glycosides are usually weaker than those of aglycones, but the bioavailability is occasionally enhanced by glucose (Londoño-Londoño et al., 2010). Therefore, there might be higher content of flavonoids in aglycone form present in the samples undergone steaming for 6 to $10 \mathrm{mins}$ compared to other samples.

\section{Conclusion}

Steaming time showed a significant effect on the total phenolic and flavonoid contents and antioxidant activity of Napier grass based on DPPH, FRAP, FTC and TBA assays. Napier grass steamed for 8 mins showed the highest value of phenolic and flavonoid content in both analyses. It also showed high antioxidant activity in DPPH, FRAP, FTC and TBA assays. Therefore, 8 mins of steaming time is suitable for the preparation of Napier grass herbal green tea. The dissimilarity of the results might be due to the different antioxidant mechanisms of the methods used or variations of the sample ability to scavenge free radicals.

\section{Conflict of Interest}

Authors declare no conflict of interest.

\section{Acknowledgments}

This research was supported by Universiti Malaysia Terengganu. The authors would like to thank the UMT's central lab and PPSTM for the facilities provided to conduct the study.

\section{References}

Adefegha, S.A. and Oboh, G. (2011). Cooking enhances the antioxidant properties of some tropical green leafy vegetables. African Journal of Biotechnology, 10(4), 632-639.

Akah, N.P. and Ani, J.C. (2014). The role of elephant grass (Pennisetum purpureum L.Schumach) "achara" in global food security. International Conference on Biodiversity and the UN Millennium Development Goals: Biodiversity and Food Security. Aix-enProvence, France: French CNRS Institut Ecologie et Environnement (InEE) and the German Leibniz Association (WGL).
Akah, N.P. and Onweluza, J.C. (2014). Evaluation of water-soluble vitamins and optimum cooking time of fresh portions of elephant grass (Pennisetum purpureum L. Schumach) shoot. Nigerian Food Journal, 32(2) 120-127. https://doi.org/10.1016/ S0189-7241(15)30127-2

Andres-Lacueva, C., Monagas, M., Khan, N., IzquierdoPulido, M., Urpi-Sarda, M., Permanyer, J. and Lamuela-Raventós, R.M. (2008). Flavanol and flavonol contents of cocoa powder products: Influence of the manufacturing process. Journal of Agricultural and Food Chemistry, 56, 3111-3117. https://doi.org/10.1021/jf0728754

Arora, R.K. (2014). Diversity in underutilized plant species - an Asia Pacific perspective., p. 203. New Delhi, India: Bioversity International.

Balasundram, N., Sundram, K. and Samman, S. (2006). Phenolic compounds in plants and agri-industrial byproducts: Antioxidant activity, occurrence, and potential uses. Food Chemistry, 99(1), 191-203. https://doi.org/10.1016/j.foodchem.2005.07.042

Bamidele, O.P., Fasogbon, M.B., Adebowale, O.J. and Adeyanju, A.A. (2017). Effect of blanching time on total phenolic antioxidant activities and mineral content of selected green leafy vegetables. Current Journal of Applied Science and Technology, 24(4), 1 -8. https://doi.org/10.9734/CJAST/2017/34808

Barku, V.Y.A., Opoku-Boahen, Y., Owusu-Ansah, E. and Mensah, E.F. (2013). Antioxidant activity and the estimation of total phenolic and flavonoid contents of the root extract of Amaranthus spinosus. Asian Journal of Plant Science and Research, 3(1), 69-74.

Bennett, L.L., Rojas, S. and Seefeldt, T. (2012). Role of antioxidants in the prevention of cancer. Journal of Experimental and Clinical Medicine, 4(4), 215-222. https://doi.org/10.1016/j.jecm.2012.06.001

Benzie, I.F.F. and Strain, J.J. (1996). The ferric reducing ability of plasma (FRAP) as a measure of "antioxidant power": The FRAP assay. Analytical Biochemistry, 239(1), 70-76. https:// doi.org/10.1006/abio.1996.0292

Brito, A., Areche, C., Sepúlveda, B., Kennelly, E.J. and Simirgiotis, M.J. (2014). Anthocyanin characterization, total phenolic quantification and antioxidant features of some Chilean edible berry extracts. Molecules, 19(8), 10936-10955. https:// doi.org/10.3390/molecules190810936

Carloni, P. Tiano, L. Padella, L., Bacchetti, T., Customu, C., Kay, A. and Damiani, E. (2013). Antioxidant activity of white, green and black tea obtained from the same tea cultivar. Food Research International, 53, 900-908. https://doi.org/10.1016/ j.foodres.2012.07.057 
Chumyam, A., Whangchai, K., Jungklang, J., Faiyue, B. and Saengnil, K. (2013). Effects of heat treatments on antioxidant capacity and total phenolic content of four cultivars of purple skin eggplants. ScienceAsia, 39, 246-251. https://doi.org/10.2306/ scienceasia1513-1874.2013.39.246

Dewanto, V., Wu, X. and Liu, R.H. (2002). Processed sweet corn has higher antioxidant activity. Journal of Agricultural and Food Chemistry, 50, 4959-4964. https://doi.org/10.1021/jf0255937

Duthie, G.G. and Bellizzi, M.C. (1999). Effects of antioxidants on vascular health. British Medical Bulletin, 55(3), 568-577. https:// doi.org/10.1258/0007142991902637

Geetha, K., Hulamani, S. and Shivaleela, H.B. (2018). Effect of cooking on total antioxidant activity, polyphenols and flavonoid content in commonly consumed vegetables. International Journal of Current Microbiology and Applied Sciences, 7(2), 1459-1466.

Gramza, A., Korczak, J. and Amarowicz, R. (2005). Tea polyphenols - their antioxidant properties and biological activity - a review. Polish Journal of Food and Nutrition Sciences, 14(55), 219-235. https://doi.org/10.20546/ijcmas.2018.702.176

Gunathilake, K.D.P.P. and Ranaweera, K.K.D.S. (2016). Antioxidative properties of 34 green leafy vegetables. Journal of Functional Foods, 26, 176186. https://doi.org/10.1016/j.jff.2016.07.015

Hashemi, M., Behrangi, N. and Farahani, E. (2014). Bioinformatic analysis for anticancer effects of flavonoids in vegetables and fruits. International Conference on Biological, Civil and Environmental Engineering (BCEE-2014) March 17-18. Dubai (UAE): International Institute of Chemical, Biological and Environmental Engineering

Heong, C.S., Kaur, Bhupinder, Huda, N., Karim, A.A. and Fazilah, A. (2011). Effect of fermentation on the composition of Centella asiatica teas. American Journal of Food Technology, 6(7), 581-593. https:// doi.org/10.3923/ajft.2011.581.593

Hui, Y.H., Meunier-Goddik, L., Josephsen, J., Nip, W.K. and Stanfield, P.S. (2004). Handbook of food and beverage fermentation technology. Boca Raton: CRC Press. https://doi.org/10.1201/9780203913550

Hwang, I.G., Shin, Y.J., Lee, S., Lee, J. and Yoo, S.M. (2012). Effects of different cooking methods on the antioxidant properties of red pepper (Capsicum annuum L.). Preventive Nutrition and Food Science, 17, 286-292. https://doi.org/10.3746/ pnf.2012.17.4.286

Irina, I. and Mohamed, G. (2012). Biological activities and effects of food processing on flavonoids as phenolic antioxidants. In Petre, M. (Ed.), Advanced in Applied Biotechnology, p. 101-124. InTech Open. https://doi.org/10.5772/30690

Kalkan, I. and Yücecan, S. (2013). Stability of dietary phenolics and antioxidant properties of vegetables depends on cooking methodology. Journal of Marmara University Institute of Health Sciences, 3 (1), $\quad 8-16 . \quad$ https://doi.org/10.5455/ musbed.20130118092619

Kamtekar, S., Keer, V. and Patil, V. (2014). Estimation of phenolic content, flavonoid content, antioxidant and alpha amylase inhibitory activity of marketed polyherbal formulation. Journal of Applied Pharmaceutical Science, 4(9), 61-65.

Kessy, H.N.E., Hu, Z., Zhao, L. and Zhou, M. (2016). Effect of steam blanching and drying on phenolic compounds of litchi pericarp. Molecules, 21(6), 1-9. https://doi.org/10.3390/molecules21060729

Khan, F., Garg, V.K., Singh, A.K. and Kumar, T. (2018). Role of free radicals and certain antioxidants in the management of Huntington's disease: a review. Journal of Analytical and Pharmaceutical Research, 7(4), 386-392. https://doi.org/10.15406/ japlr.2018.07.00256

Kulišić, T., Dragović-Uzelac, V. and Miloš, M. (2006). Antioxidant activity of aqueous tea infusions prepared from oregano, thyme and wild thyme. Food Technology and Biotechnology, 44(4), 485-492.

Lin, D., Xiao, M., Zhao, J., Li, Z., Xing, B., Li, X., Kong, M., Li, L., Zhang, Q., Liu, Y., Chen, H., Qin, W., Wu, H. and Chen, S. (2016). An overview of plant phenolic compounds and their importance in human nutrition and management of type 2 diabetes. Molecules, 21(10), 1374. https://doi.org/10.3390/ molecules 21101374

Londoño-Londoño, J., de Lima, V.R., Lara, O., Gil, A., Pasa, T.B.C., Arango, G.J., and Pineda, J.R.R. (2010). Clean recovery of antioxidant flavonoids from citrus peel: Optimizing an aqueous ultrasoundassisted extraction method. Food Chemistry, 119(1), 81-87. https://doi.org/10.1016/ j.foodchem.2009.05.075

Lowe, A.J., Thorpe, W., Teale, A. and Hanson, J. (2003). Characterisation of germplasm accessions of Napier grass (Pennisetum purpureum and P. purpureum x $P$. glaucum hybrids) and comparison with farm clones using RAPD. Genetic Resources and Crop Evolution, 50(2), 121-132. https://doi.org/10.1023/ A:1022915009380

Lusia Barek, M., Hasmadi, M., Zaleha, A.Z. and Mohd Fadzelly, A.B. (2015). Effect of different drying methods on phytochemicals and antioxidant properties of unfermented and fermented teas from Sabah Snake Grass (Clinacanthus nutans Lind.) leaves. International Food Research Journal, 22(2), 
661-670.

Mondal, T.K. (2007). Tea. In Devey M.R. and Pua, P. (Eds.). Biotechnology in agricultural and forestry: Transgenic crops V. Vol. 60., p. 519-536. Germany: Springer.

Moyo, S.M., Kayitesi, E., Mavumengwana, V. and Madala, N.E. (2016). Effects of cooking and drying on the total phenolic, total flavonoid content, antioxidant and antibacterial activity of Cleome gynandra (Spider plant). International Conference on Advances in Science, Engineering, Technology and Natural Resources (ICASETNR-16) November 24 25. South Africa: International Academy of Chemical, Civil and Environmental Engineering.

Nartnampong, A., Kittiwongsunthon, W. and Porasuphatana, S. (2016). Blanching process increases health promoting phytochemicals in green leafy Thai vegetables. International Food Research Journal, 23(6), 2426-2435.

Nobosse, P., Fombang, E.N. and Mbofung, C.M.F. (2017). The effect of steam blanching and drying method on nutrients, phytochemicals and antioxidant activity of Moringa (Moringa oleifera L.) leaves. American Journal of Food Science and Technology, 5(2), 53-60.

Nyambati, E.M., Lusweti, C.M., Muyekho, F.N. and Mureithi, J.G. (2011). Up-scalling napier grass (Pennisetum purpureum Schum.) production using "Tumbukiza" method in smallholder farming systems in Northwestern Kenya. Journal of Agricultural Extension and Rural Development, 3(1), $1-7$.

Preti, R., Rapa, M. and Vinci, G. (2017). Effect of steaming and boiling on the antioxidant properties and biogenic amines content in green brean (Phaseolus vulgaris) varieties of different colours. Journal of Food Quality, 2017, 1-8. https:// doi.org/10.1155/2017/5329070

Rani, K. (2017). Role of antioxidants in prevention of diseases. Journal of Applied Biotechnology and Bioengineering, 4(1), 495-496. https:// doi.org/10.15406/jabb.2017.04.00091

Rodrigues, M.J., Neves, V., Martins, A., Rauter, A.P., Neng, N.R., Nogueira, J.M.F., Varela, J., Barreira, L. and Custódio, L. (2016). In vitro antioxidant and anti -inflammatory properties of Limonium algarvense flowers' infusions and decoctions: A comparison with green tea (Camellia sinensis). Food Chemistry, 200, 322-329. https://doi.org/10.1016/ j.foodchem.2016.01.048

Sadowska-Bartosz, I. and Bartosz, G. (2014). Effect of antioxidants supplementation on aging and longevity. BioMed Research International, 2014, 117. https://doi.org/10.1155/2014/404680
Saikia, S. and Mahanta, C.L. (2013). Effect of steaming, boiling and microwave cooking on the total phenolics, flavonoids and antioxidant properties of different vegetables of Assam, India. International Journal of Food and Nutritional Sciences, 2(3), 4753.

Sarla, S., Prakash, M.A., Apeksha, R. and Subhash, C. (2011). Free radical scavenging (DPPH) and ferric reducing ability (FRAP) of Aphanamixis polystachya (Wall) Parker. International Journal of Drug Development and Research, 3(4), 271-274.

Singh, V., Verma, D.K. and Singh, G. (2014). Processing technology and health benefits of green tea. Popular Kheti, 2(1), 23-30.

Thilakarathna, S.H. and Rupasinghe, H.P.V. (2013). Flavonoid bioavailability and attempts for bioavailability enhancement. Nutrients, 5(9), 33673387. https://doi.org/10.3390/nu5093367

Turkmen, N., Sari, F. and Velioglu, Y.S. (2009). Factors affecting polyphenol content and composition of fresh and processed tea leaves. Akademik Gida, 7(6), 29-40.

Udaya Prakash, N.K., Ranjithkumar, M., Sripriya, N., Pujitha Lakshmi, R., Deepa, S. and Bhuvaneswari, S. (2014). Antioxidant, free radical scavenging activity and GC-MS studies on Pedilanthus tithymaloides (L.) poit. International Journal of Pharmacy and Pharmaceutical Sciences, 6(11), 284-287.

Ukpabi, U.J., Ofoeze, M.A., Uchechukwu, N., Ezeama, C.F., Edoga, H. and Nwosu, K.I. (2015). Potentials $\mathrm{f}$ naturally sheathed young leaves of Napier grass (Pennisetum purpureum) varieties as feeding materials in Nigeria. American Journal of Agricultural Science, 2(3), 97-102.

Wiczkowski, W. and Piskula, M.K. (2004). Food flavonoids. Polish Journal of Food and Nutrition Sciences, 13(54), 101-114.

Young, I.S. and Woodside, J.V. (2001). Antioxidants in health and disease. Journal of Clinical Pathology, 54 (3), 176-186. https://doi.org/10.1136/jcp.54.3.176

Yuniartini, N.L.P.S., Kusnadi, J. and Zubaidah, E. (2015). The effect of various tea processing methods on antioxidant activity of guava (Psidium guajava $\mathrm{L}$. Var Pomifera) leaves tea in east Java Indonesia. International Journal of PhermTech Research, 7(4), 580-586.

Zhang, Y.J., Gan, R.Y., Li, S., Zhou, Y., Li, A.N., Xu, D.P. and Li, H.B. (2015). Antioxidant phytochemicals for the prevention and treatment of chronic diseases. Molecules, 20(12), 21138-21156. https://doi.org/10.3390/molecules201219753 